\title{
Azevedo Marques: o homem (*)
}

\section{Ernesto Leme}

Aos 11 de abril de 1865, o cura da Sé de São Paulo, Marcellino Ferreira Bueno, um dos trinta e tres primeiros' estudantes que aqui se matricularam, em 1828, batizava e punha os santos óleos em um menino de cincoenta e um dias, nascido nesta Capital a 19 de fevereiro e que recebeu o nome de José. Eram seus pais Joaquim Candido de Azevedo Marques e sua mulher d. Rita Peixoto de Mello e Azevedo Marques, servindo-lhe de padrinhos seu avô materno, major Fabricio Peixoto de Mello e sua avó paterna, d. Joaquina Eufrasia Xavier de Azevedo.

No lar venturoso em que florescia a bênção desse filho, duas heranças magnificas lhe estavam reservadas: a honradez e a inteligência. Provinha em linha reta, como o revelou a pesquiza de Bueno DE Azevedo Filho, de Nicoláu de Souza Fernando e de sua mulher d. Ana Marques, um dos sessenta casais que foram, em 1718, povoar a colonia do Sacramento. Um neto de Nicoláu Fernando, o capitão-mór Manuel de Azevedo Marques, casado com d. Ana Marques Vitorina, foi pai de Manuel Eufrasio de Azevedo Marques, nascido na colonia do Sacramento em 1764 e falecido nesta Capital em 24 de novembro de 1809. Formado em direito na Universidade de Coimbra, aqui chegou em 1791, abrindo escritório de advocacia, "profissão exclusiva de toda a sua vida, e na qual adquiriu reputação a que tinha direito pela

(*) Discurso proferido, na sessão comemorativa do falecimento do professor Azevedo Marques, realizada em 24 de maio de 1944, na sala "João Mendes Junior", da Faculdade de Direito. 
sua ilustração e probidadê", (Manuel Eufrasio de AzevEDO MARQUES, Apontamentos históricos, geográficos, biográficos, estatísticos e noticiosos da Provincia de S. Paulo, Rio de Janeiro, 1879, II, 61). O fốro paulistano contava então, infórma o cronista, tres advogados sómente: MANUEL EUfrasio, Arouche Rendon e Nicoláu Pereira de Campos Vergueiro, entre êles se repartindo as tarefas profissionais.

Casado com d. Ana Gertrudes de Jesus, filha de João Francisco de Abreu e de d. Eufrasia Maria de Jesus, teve nove filhos: Manuel Eufrasio, Ana Eufrasia, Maria Candida, Antonio Mariano, Joaquim Manuel, Francisco Marciano, José Xavier, Ana Benedita e João Mariano. O sétimo dêles, José Xavier de Azevedo Marques, batizado nesta Capital aos 14 de maio de 1805 e falecido, como inspetor aposentado da Tesouraria da Fazenda de São Paulo, em 24 de julho de 1872, casou-se com sua prima, d. Joaquina Eufrasia Xavier de Azevedo e foi avô do nosso homenageado. Dois de seus irmãos, Manuel Eufrasio e Antonio Mariano, pertencem à historia desta Casa: Avellar Brotero, primeiro lente nomeado para esta Faculdade, servindo de secretario, inscreve-os, respectivamente, como ns. 18 e 31, na turma dos primeiros estudantes, que vieram frequentar as aulas do curso jurídico.

Cincoenta e tres anos após, dia por dia, ao encerramento da matrícula desse grupo inicial de alunos, aos 31 de março de 1881, José MANuel de Azevedo Marques requeria sua inscrição no primeiro ano. Fizera seus preparatorios no Curso Anexo, sendo aprovado plenamente em francês, em 26 de novembro de 1878, plenamente em português, tres dias depois, aprovado em Retórica e Poética, aos 14 de fevereiro de 1879, em geografia, a 4 de março, plenamente em latim, a 4 de dezembro, plenamente em história, a 27 de fevereiro de 1880, plenamente em inglês, a 20 de março, aprovado em filosofia, aos 8 de fevereiro de 1881, plenamente em aritmética, aos 12 de fevereiro e plenamente em geometria, aos 30 de março.

Iniciava o jovem acadêmico o seu curso sob os melhores auspícios. Entre os cento e trinta e tres rapazes, matri- 
culados nesse ano, contavam-se alguns que haviam de deixar um rasto luminoso de sua passagem, no parlamento, na judicatura, nos postos de governança, no professorado, nas letras, na advocacia: Estevam de Almeida, Veiga Filho, Pinto de Toledo, Jesuino Gardoso, Enéas Galvão, Borges de Medeiros, Cincinato Braga, Primitivo Sette, Saraiva Junior, José de Campos Novars, João Leite Ribeiro Junior, Luiz AUgusto Pereira de Araujo, Juvenal Malheiros, Fortunato dos Santos Moreira, Joaquim Augusto Gomide, João Baptista de Oliveira Penteado, Ismael Dias da' Silva, Raul Pompeia, luiz Murat... Notava-se mais, no meio dos caloiros, que se movimentavam pelas Arcadas, nesse ano da graça de 1881, antonio Cândido de Camargo que, trocando as letras de Ulpiano pelos conselhos de Hipócrates, tornar-se-ia em São Paulo mestre consumado na cirurgia, modelo e guia de cirurgiões.

O noviciado desses primeiranistas, no estudo do direito, fez-se sob a direção de dois mestres notabilissimos: Sá e Benevides, em direito natural; Duarte de Azevedo, em direito romano. Jubilado este, por decreto de 28 de maio, substituiu-o na cátedra Dutra Rodrigues, nomeado por decreto de 25 de junho e empossado a 4 de julho.

Não precisarei dizer-vos quem foram esses professores, glorias autênticas desta Academia. Não me furto, porém, ao prazer de vos relatar um episódio, que me foi referido em Porto Alegre, pelo professor Leonardo Macedonia, quando, em novembro de 1940, lá estive, integrando a banca examinadora do concurso de direito civil, na Faculdade de Direito.

Estavamos na Monarquia. SÁ e Benevides proferia nesta Escola magnifica lição sobre o Poder Moderador, em face da Carta Constitucional de 1824. Criticava o preeminencia dada ao Imperador, pelas nórmas constitucionais então vigentes, quando inopinadamente, abre-se a porta da sala e entra, acompanhado por pequena comitiva, sua majestade d. Pedro II. Sá e Benevides ergue-se, com a classe, para saudá-lo. E o monarca pede ao mestre prossiga em sua 
aula, pois deseja assistí-la... Sem vacilar, faz Benevides breve resumo da materia exposta e continúa, no mesmo tom, a preleção interrompida. Ao terminar, volta-se respeitoso para o Imperador e lhe diz, textualmente: “E' esta, Real Senhor, a doutrina da cadeira, em que pese a Vossa Majestade"... Pedro II dirige-se para o lente e, estendendo-lhe a mão, responde-lhe, a sorrir: "Senhor doutor SÁ E BenEvides, eu o conhecia como homem de ilustração e de talento; vejo que é tambem um homem de carater"...

Foi sob a direção de homens de tal pórte, que José MAnuel de Azevedo Marques fez o seu quinquenio acadêmico. Plenificado sempre, recebeu, a 16 de março de 1886, o gráu de bacharel.

Nomeado promotor público da comarca de Batatais, aos 28 de maio desse ano, passou a juís municipal e de órfãos do mesmo termo, por decreto de 28 de maio de 1887. Exercia esse cargo quando, aos 19 de fevereiro de 1889 pelas tres e meia da tarde, em oratório particular, na fazenda "Invernada", termo e paróquia de Sant'Ana dos Olhos d'Agua, contraíu matrimônio com uma gentil menina de quinze anos de idade, - Ana Claudina, - filha do capitão Francisco Marcellino Diniz Junqueira e de d. Maria de Paula Franco Junqueira. Juiz de direito de Franca, por decreto de 7 de novembro de 1890, foi removido para Batatais, a 6 de junho de 1891.

Organizado constitucionalmente o Estado, o Congresso Legislativo decretou a lei n. 18, de 21 de novembro de 1891, sobre o poder judiciario. Essa lei foi alterada pela de n. 80 , de 25 de agosto de 1892, regulamentada pelo decreto n. 123 , de 10 de novembro do mesmo ano.

Entre os dispositivos da lei n. 80, contava-se o do art. 2. , assim concebido: "Fica dispensado o concurso para as nomeações de juizes de direito, na organização da magistratura do Estado. 0 presidente do Estado preferirá para essas nomeações, tanto quanto convenha aos interesses da melhor composição da magistratura, os juises de direito que funcionarem ou houverem funcionado no Estado". 
Era presidente de São Paulo, a esse tempo, Bernardino de Campos. Ocupava a pasta da Justiça, em seu governo, Manuel Pessoa de Srqueira Campos. E, na composição da magistratura do Estado, então organizada, não houve um lugar para o jovem juís de direito de Batatais, então no esplendor de seus vinte e sete anos...

Qual a explicação desse misterio? Coisas da política... José Jacintho Ribeiro, em sua Cronologia Paulista, II, 2. ${ }^{a}$ parte, p. 355, ao traçar a biografia de Azevedo Maroues, conta apenas que êle "deixou a carreira da magistratura, quando organizada a do Estado, mudando-se para a Capital onde se dedicou à advocacia".

Penso que o arcano permanece imperscrutavel até hoje e posso desvendá-lo; estribo-me em confidencia do proprio Azevedo Marques, cujo convivio foi um doce encanto que perdi. Era êle deputado federal quando, de uma feita, conversando com o conselheiro Rodrigues Alves, então presidente da República, este se atribuiu, repêso, a culpa do não aproveitamento do mestre, na organização judiciaria de 1892... Mas, com aquela fidalguia de sempre, que era o seu melhor apanagio, Azevedo Marques redarguiu: "Senhor conselheiro, ignorava dever-lhe esse obsequio. $O$ ato do governo de São Paulo obrigou-me a dar rumo diverso à minha vida, com o que sómente tive de lucrar"...

Lucrou muito, com ef eito; e, com êle, lucraram as letras jurídicas e o serviço da patria.

Para êle, ser juís verdadeiro afigurava-se-lhe "o maior privilegio que o Destino possa outorgar". Juís que fosse o resto da existencia, seria, sem dúvida, um magistrado modelar, glorificando a sua toga e enaltecendo a sua classe. Não alcançaria, comtudo, a projeção que obteve, como advogado, como parlamentar, como jurisconsulto, como professor de direito, como ministro de Estado.

Eleito por 32.544 votos, no pleito de $1 .^{\circ}$ de dezembro de 1897, deputado ao Congresso Estadual, para a legislatura de 1898-1900, os Anais da Câmara Legislativa guardam os écos de sua fulgurante passagem por essa Casa. Já na ses- 
são preparatoria de 31 de março de 1898 , o presidente Luís Pisa nomeava-o, juntamente com Pereira de QueIroz e CaNdido MotTa, para compor a comissão especial que teria de organizar a lista dos deputados cujos diplomas não haviam sofrido contestação, bem como daqueles cuja eleição tivesse sido contestada. No dia seguinte, a Câmara o escolhia para a comissão de cinco membros, que devia examinar as atas eleitorais e a 9 de abril para a sexta comissão permanente, - Agricultura, Colonização e Imigração.

Ao se iniciarem as sessões, no ano seguinte, investem-no os seus pares no posto de vice-presidente da Câmara, por 31 votos contra 1, dado ao sr. Padua Salles. Quer excusar-se à honraria, mas a assembléa rejeita a sua renuncia, unanimemiente, dando-lhe, dessa fórma, uma decidida demonstração de seu apreço. Na sessão de 9 de abril de 1900. é reeleito para esse cargo.

O novel deputado não se esquece de sua condição de antigo membro do poder judiciario. Falando a 27 de agosto de 1898 , sobre o projeto n. 6 , de 1895 , propondo melhoria dos vencimentos dos juíses de direito, acentuava: "Nós todos, representantes do Estado, temos mandato direto ou indireto em relação a todos os negocios atinentes ao serviço público do mesmo Estado. Eu, porém, sr. presidente, me considero em uma posição especial; considero-me tendo um mandato respecial, porque, pertencendo à magistratura, não posso deixar de ser neste Congresso um advogado, embora incompetente (nâo apoiados gerais), dessa classe". Deputado federal, alega na tribuna, a 17 de setembro de 1901, sua qualidade de ex-juís, para sustentar, em nome da classe a que pertenceu, emenda ao projeto em discussão, isentando de impostos os vencimentos dos magistrados do Distrito Federal.

Sua atividade, na Câmara Estadual, é permanente e brilhante. Apresenta à consideração da Casa o projeto de lei n. 38, de 1898, estabelecendo modificações no processo civil; com Eduardo Garcia, o projeto n. 88, desse mesmo ano, autorizando o governo a dispender a quantia de Rs. 30:000\$000, no aumento e refórma da cadeia pública de 
Batatais; pelas comissões reunidas de Fazenda e Agricultura, o projeto $n .123$, de 1898 , tendente a incentivar a industria agrícola da goma elástica; o projeto n. 2 , de 1899 , sobre férias forenses; o projeto n. 10 , desse mesmo ano, autorizando o governo do Estado a rever o regulamento do sêlo estadual e fixando nórmas para essa revisão; com Alfredo Pujol, o projeto n. 71 , de 1899 , aumentando os vencimentos dos juíses de direito do Estado.

Frequenta a tribuna assiduamente. E todos os assuntos de interesse público lhe despertam a atenção: assim o processo civil, como a organização judiciaria; as férías forenses, como os vencimentos dos magistrados; o regulamento do sêlo, como a questão dos vencimentos dos delegados de policia da Capital; o crédito agrícola, como a estatística dos cafesais; a introdução de imigrantes no Estado, como a cultura da mangabeira; a reconstrução do teatro São José, recursos municipais, criações de escolas, a divisão do cartorio de protestos. A tudo atende com igual interesse e competencia.

E assim com pesar que os seus colegas de Câmara vêem-se privados de sua colaboração, logo após. Elege-o o sétimo dístrito deputado federal, a 31 de dezembro de 1899, oferecendo a Azevedo Marques um mais amplo cenario, para demonstração de sua alta capacidade.

Logo que a Câmara se instala, é o jovem deputado, então com trinta ie cinco anos, designado para a Comissão de Constituição, Legislação e Justiça, sendo, dentre todos os membros desta, o mais votado. Mais tarde, integra a Comissão do Código Civil.

Oferece projetos de lei sobre os proprios nacionais, regulàmentando o art. 64, parágrafo único, da Constituição, sobre a competencia dos Estados de legislar sobre processo, sobre a precedencia obrigatoria do casamento civil ao religioso.

$\mathrm{Na}$ elaboração do Código, o seu trabalho foi verdadeiramente notavel. "A Comịssão dos 21", escreve PAulo DE LACERDA, "foi o cadinho em que mais se apurou o conteúdo jurídico do projeto. De fato, a inesgotavel atividade do 
seu presidente, a dedicação metódica e esclarecida dos relatores parciais, a interferencia valiosissima de personagens estranhos à Câmara nas discussões orais, tudo concorreu para tornar esta fase a mais fecunda e brilhante da trabalhosa organização do Código". Coube a Azevedo Marques relatar o Parecer preliminar sobre o Plano geral do projeto; a parte sobre Direito Internacional Privado; e a Parte Geral, sobre Pessoas e Coisas. E, de como se houve no desempenho dessa missão, dizem os seus trabalhos, constantes dos Anais da Câmara. Melhor que tudo, entanto, fala a respeito o seguinte incidente, quase desconhecido.

Entre os eminentes jurisperitos, estranhos ao Parlamento, que participavam das reuniões da Comissão dos 21, contava-se ANDrade Figueira. Respeitado por sua idade provecta e por seu grande saber, era permanente o máu humor do Conselheiro. Adversario irreconciliavel do regime, não acreditava na eficacia dos trabalhos da Câmara, empenhada na feitura do Código. Um dia, porěm, na sala da Comissão Especial, presidida por SEABRA, ouve uma exposição do deputado Azevedo Marques, sobre parte do projeto, que lhe fôra distribuida. O venerando Conselheiro exulta de satisfação. Impecavel o trabalho, no fundo e na fórma. Principios jurídicos indisputaveis. Argumentação convincente... Entusiasmado, volta-se para os que lhe estavam próximos e exclama: "Não é que estes rapazes da República tambem sabem o seu direito civil?"

Toda a Câmara, seduzida pela finura de trato e pela insuperavel cortezia de Azevedo Marques, a quem Pelagio Lово apelidou, com justeza, - "mestre de processo e modelo de bôas maneiras", - passa a admirar o jurista eximio e orador atraentissimo, que falava como se estivesse conversando, despretencioso e cristalino. E toda a assembléa se põe a seu lado quando, agredido grosseira e injustamente pelo deputado gaúcho Alfredo Varella, dá-lhe, em sessão de 6 de novembro de 1903, uma réplica enérgica e esmagadora. 0 parlamentar riograndense, que foi acabar, afinal, na quietude de um consulado, não ergue a luva do desafio, 
tentando ao menos provar a insinuação malévola de seu discurso. E os Anais documentam a leviandade de seu proceder, que serviu apenas para mais exaltar a lisura e a nobreza de atitudes de José Manuel de Azevedo Marques.

Findo o seu mandato, dedica-se à advocacia, nesta Capi tal. Aqui mantém um dos mais conceituados e procurados escritórios da época. Constante atividade científica, fartamente revelada pela imprensa diaria e pelas páginas do "São Paulo Judiciario". Em 1912, Plinio Barreto, redator forense d"“O Estado de São Paulo", e que já nos déra dois proveitosos volumes de suas crônicas, de 1910 e 1911, inicia a publicação da "Revista dos Tribunais", que já fórma cento e quarenta e oito volumes. No volume 12 , página 69 , encontra-se o primeiro trabalho de Azevedo Marques: "A hipoteca não se extingue pela arrematação, salvo em casos especiais", com que inaugura uma colaboração, que sómente haveria de cessar nos seus derradeiros mêses de vida. Foi mesmo, digo-o sem temor de engano, o mais fiel dentre os colaboradores da "Revista", nos seus trinta e dois anos de existencia. Uma semana após haver deixado o cargo de ministro das Relações Exteriores, lá aparecia, para entregar um artigo, com que reiniciava a sua atividade jurídica... Foi o que nos contou NoÉ Azevedo, na sessão que a Ordem dos Advogados dedicou à memoria do mestre, no proprio dia do seu enterramento.

Em 1911, com uma dissertação sobre "A prescrição extintiva das dívidas passivas da Fazenda Nacional", além de outros trabalhos, disputa a livre-docencia na Faculdade de Direito, nos termos do decreto federal n. 8.662, de 5 de abril do mesmo ano. Julgado habilitado e nomeado, a 22 de março de 1912, passa a professor extraordinario efetivo da sétima secção, a 31 de julho, tomando posse a 10 de agosto.

Por decreto de 15 de outubro de 1913, é nomeado professor ordinario de Teoria e prática do processo criminal, tomando posse da cadeira a 24. Em 24 de agosto de 1916, é declarado professor catedrático da mesma disciplina, cargo esse no qual se aposenta a 16 de setembro de 1925 . 
Da missão do professor falou êle, lindamente, anos mais tarde, dando conselhos a um antigo discípulo, que conquistára, tambem, uma cátedra nesta Faculdade. "O professor é um modelo, bom, se êle for bom, e por isso assume graves funções sociais. Não póde descansar, paralisar, ler e repetir, anos a fio, as notas do seu canhenho, não póde apostilar porque deve ser um apóstolo, elemento formativo dos magistrados da justiça. Nâo sendo méramente um repetidor, êle precisa de ser um crítico para ensinar a criticar com individualidade, com a filosofia, a moral, a lógica, a historia, o patriotismo e a arte". Como pontificava, o dom de transmissão é "qualidade primacial, temperamento imprescindivel do verdadeiro professor"...

$\mathrm{E}$ as suas preleções tinham a transparencia da simplicidade, - claras, incisivas, convincentes. Não procurava em aula, nem nos seus escritos, como disse no prefacio de um de seus livros, a "interpretação das fontes"; preferia antes "a interpretação do proprio direito".

Ensinava êle precisamente à minha turma de bacharelandos quando, a 28 de julho de 1919, o presidente Epitacio Pessoa nomeou-o ministro de Estado das Relações Exteriores, cargo esse em que se manteve até o fim do governo, a 15 de novembro de 1922.

Político e diplomata habilíssimo, não era Azevedo MARQUEs, comtudo, um hómem da "carrière". Nem era tambem profissionalmente um diplomata o sr. Epitacio Pessoa, o que lhe não impedia de o ser de maneira completa, por indole e por inspiração. De monsenhor Pio Dos SANTos, recemchegado da Europa e a quem fui ouvir, pela "Gazeta de Noticias", onde então trabalhava, logo após a viagem triunfal do embaixador do Brasil à Conferencia da Paz, pela Bélgica, Italia, Inglaterra, Portugal, Estados Unidos e Canadá, - colhi a impressão de maravilha, deixada pelo sr. EPITacio Pessoa no Vaticano, pela finura com que soubéra, nessa oportunidade, conjugar as exigencias do protocólo eclesiástico, com as do protocólo civil. 
Duas questões preocuparam, precipuamente, no'sso representante em Versalhes: a do café de São Paulo, vendido por ordem do governo do Estado e cujo produto se encontrava depositado na casa $\mathrm{S}$. Bleischroeder e a do confisco dos navios ex-alemães, uma e outra regulada no Tratado de Paz, arts. 263 e 297. Se a primeira ficára, ao menos aparentemente, solucionada no Pacto, a segunda dependia de negociações ientre os países interessados e decisão da Comissão de Reparações, de acordo com o proprio Tratado te o protocólo Wilson-Lloyd George. E soube o ministro de Estado, ao qual estavam afetos esses problemas, conduzí-los, em meio às dificuldades existentes, com seguro criterio e sabedoria.

Mas, além desses, outros assuntos requeriam a atenção do chanceler, nesse intrincado após-guerra: a liquidação das obrigações pecuniarias, referidas no art. 296 do Tratado de Versalhes, por intermedio dos clearing-officies; a questão de bens de brasileiros na Alemanha e de alemães no Brasil; a repatriação dos alemães aqui internados; o restabelecimento das relações políticas e comerciais com a Alemanha; o tratado firmado com a Inglaterra, para creação de uma Comissão de Paz; a constituição do Tribunal Arbitral Brasil-Alemanha; os estudos referentes à proposta boliviana, para alteração do art. 7. ${ }^{\circ}$ do Tratado de Petrópolis; negociações com o mesmo país, sobre trechos da linha limítrofe; acordo com ò Perú, para restabelecimento da Comissão Mixta de demarcação da fronteira; os trabalhos da Comissão Mixta de limites com o Uruguai; os trabalhos relativos à ponte internacional, sobre o rio Jaguarão; os tratados de comercio com a Italia, Uruguai e Bélgica; a convenção com o prīmeiro desses países sobre emigração e trabalho: acordos com o México e Paraguai, sobre transporte de correspondencia diplomática; convenção com os Estados Unidos sobre vales postais; aprovação da convenção de 1912, em Haia, sobre direito cambial; o estudo sobre o aproveitamento das quédas do Iguassú, para captação de energia hidro-elétrica; a convenção relativa ao comercio de armas e munições: tra- 
tado de extradição com o Paraguai; protocólo adicional ao tratado sobre extradição, com o Uruguai; o reconhecimento da Polonia, Tchecoslováquia, Finlandia, Islandia, República Austriaca, Armenia, Lituania, Estonia e Letonia; a representação do Brasil na conferencia de Barcelona, sobre liberdade de Comunicações e Trânsito, na Sexta Conferencia Parlamentar Internacional, na Segunda Conferencia Financeira Panamericana, em Washington, na Conferencia Anual do Trabalho, na Conferencia Internacional sobre Propriedade Industrial; a representação do Brasil nos centenarios da independencia do Perú, Mẻxico e Guatemala; a adesão do Brasil à convenção de Berna, de 1886, revista em Berlim em 1908, sobre Propriedade Literaria e Artística; a adesão do Brasil à União Astronômica Internacional e à União Geodésica e Geofísica Internacional; o tratado sobre dupla nacionalidade, com Portugal e a Inglaterra; ação diplomática para obter solução da pendencia sobre Tacna e Arica, entre o Chile e o Perú; o contrato da missão militar francêsa; a refórma da Secretaria de Estado das Relações Exteriores, com o estabelecimento da obrigatoriedade de concurso, pars. provimento de cargos, nas carreiras diplomática e consular: a publicação do Boletim do Ministerio...

Nessa fase de grande brilho em nossa vida internacional, instalou-se a Liga das Nações, cujo Conselho Executivo teve um representante nosso, desde a primeira reunião, efetuada em Paris a 16 de janeiro de 1920; e a assembléa da mesma organização, escolhendo os onze primeiros juises titulares, para a Côrte Permanente de Justiça Internacional, então creada, colocou entre os mesmos Ruy BARBosa, o mais votado entre todos.

Ainda durante o governo Epitacio Pessoa, sendo Azevedo Marques ministro das Relações Exteriores, o nosso país foi distinguido com a visita de suas majestades o Rei Alberto I e a Rainha Elisabeth, da Bélgica, em setembro de 1920; e, entre as numerosas e ilustres personalidades que aqui estiveram, por ocasião do centenario de nossa independencia, 
contaram-se o Secretario de Estado Norte-Americano e o presidente de Portugal, dr. Antonio José de Almeida.

A 15 de novembro de 1922, Epitacio Pesson transmitia o cargo de presidente da República ao sr. Arthur da Silva Bernardes; por seu lado, José Manuel de Azevedo Marques. deixava sereno o Itamarati, substituido pelo sr. Felix PacHECO.

Retornando a São Paulo, nova e honrosa incumbencia. lhe estava reservada: a 28 de dezembro. o Instituto dos Advogados elege-o seu presidente.

Melhor iria eu dêle aí me aproximar, anos após, quando, na presidencia Antonio Mercado, sendo eu secretario desse sodalicio, o Instituto, em reuniões diarias, iniciadas às vinte: e meia horas e que, às vezes, entravam pela madrugada, debateu o projeto de Código de Processo Civil e Comercial, em votação no Congresso do Estado e que se converteu na lei n. 2.421, de 14 de janeiro de 1930. As discussões, por proposta do sr. Vicente Ráo, unanimemente aprovada, foram orientadas pelo professor José Manuel de Azevedo Marques, escolhido relator geral.

Vieram, depois, os sucessos de 30. Pelo decreto n. 19.408, de 18 de novembro desse ano, art. 17, foi creada a Ordem. dos Advogados do Brasil, regulamentada pelo decreto $n$. 20.784, de 14 de dezembro de 1931. O sr. Plinio Barreto, então presidente do Instituto, foi eleito tambem presidenteprovisorio da Ordem dos Advogados, em São Paulo.

Quando se escrever a historia dessa instituição, em nosso Estado, ha de se conferir o relevo merecido à ação. do Primeiro Conselho, que organizou a Ordem nesta Secção ie ao zelo insuperavel de seu grande presidente. Não havia, como é óbvio, um só advogado inscrito. A Ordem não tinha secretaria, não tinha funcionarios, não tinha recursos. Aconchegou-se ao Instituto, a cuja sombra se formou. As reuniões do Conselho eram diarias, nos primeiros tempos. E, se é exato que todos os conselheiros cumpriram, galhardamente, o seu dever, nada se faria sem a prodigiosa atividade. 
alta competencia e dedicação sem par do presidente provisorio, sr. Plinio Barreto.

Eleito o novo Conselho, para a constituição definitiva da Ordem dos Advogados, cabia a este escolher os membros de sua diretoria. E não cometo indiscreção imperdoavel, lembrando que a primeira idéa, no sentido de elevar o professor José Manuel de Azevedo Marques à presidencia da Ordem, nesta Secção, partiu do proprio presidente provisorio.

Recusára o mestre, pouco antes, sua candidatura à Assembléa Nacional Constituinte, para onde os partidos coligados de São Paulo desejãam enviá-lo. Não recusaria, porém, o posto de honra, que o Conselho lhe destinava.

Estivera, ainda recentemente, na Europa. Vivera em Paris, num hotel da rue Balzac, como se estivesse em São Paulo, - no Instituto, ou na Faculdade. A revolução constitucionalista de 1932 aí encontrára Vicente Ráo; e, em consequencia dela, foram ai ter, gloriosamente exilados, FraNcisco Morato e Waldemar Ferreira.

De Paris, Azevedo Maroues seguiu para a Italia. Mussolini, informado de que o chanceler brasileiro, no governo que reconhecera a nova ordem italiana, encontrava-se em Roma, instou em recebê-lo. Azevedo Marques compareceu à audiencia do primeiro ministro, em companhia do nosso embaixador. Recebido aparatosamente, atravessou varias salas do edificio, antes de chegar ao largo gabinete do duce. Este, assentado à sua mesa de trabăhno, ergueu-se para saudar os visitantes. E, feita a apresentação de estilo, perguntou a Azevedo Marques, pomposamente, em francês: - Em que lingua deseja conversar? Ao que o antigo ministro respondeu : - Na que for do agrado de Vossa Excelencia...

A réplica desconcertou o ditador. - Eu compreendo bem o português, continuou, mas, falo-o com dificuldade; como o senhor conhece o italiano, cada um de nós falará em sua propria lingua e assim nos entenderemos. . 0 idioma de Dante e o de Camões deram-se as mãos no Palacio Veneza, nessa palestra de cortezia internacional... 
Poúco após sua elểição pára a presidencia da Ordem dos Advogados, Azevedo Mároues reuniu, num almoço íntimo, em sua residencia, os membros da antiga e da nova diretoria. Ainda aí, sua delicadeza foi tocante para comigo. Eu adoecera dias antes e, febril, não pude atender ao amavel convite. Azevedo Marques e a bonissima d. Ana, foram disso prevenidos, com antecedencia. Mas, quando os nossos companheiros chegaram, uma surpreza lhes estava reservada: à mesa da ampla sala de jantar, havia um lugar em que ninguem se assentou - o do conviva ausente, que o casal amigo quizera, em sua fidalguia, honrar dessa maneira...

A presidencia Plinio Barketo, na Ordem dos Advogados, foi a fase da iniciação; a presidencia Azevedo Margues estava destinada a ser o período das grandes realizações. A Ordem, por êle dirigida, ganhou corpo e prestigio, sendo apontada, no Conselho Federal e nos Conselhos Seccionais, como um modelo de organização.

Trabalhou-se muito aqui. Todavia, nada sobreleva, entre as conquistas obtidas, à magnifica creação da Caixa de Assistencia, idéa de Plinio Barreto, inspirada em trabalho de João Arruda, a qual a Ássembléa Legislativa do Estado tornou possivel e que Azevedo Maroues, servido por alguns devotados colaboradores, converteu em realidade.

A Ordem dos Advogados contraíu uma dívida perene com esse soberbo exemplar da especie humana, que Pelagio Lobo pintou esplendidamente como um "homem de maneiras doces e trato suave, alma de artista, figura de jurista sereno e provecto, para quem a vida só valia pelo que tem de belo e para quem os homens valiam pelo que possuem de generoso e abnegado". E foi quiçá muito mais à doçura de sua convivencia, à correção impecavel de suas maneiras e à sua aparencia fidalga, do que mesmo à similhança de um nome, que o venturoso casal deveu ser anunciado, num jornal interno de um hotel de Vichy, como sendo "Monsieur le marquis et madame la marquise d'Azevedo"... 
Consagrou o insigne mestre ao Conselho da Ordem os derradeiros dias de sua luminosa existencia. Honrava-se êle grandemente em pertencer a esta douta Congregação de professores; mas, não estimava menos, servindo-me de uma expressão muito sua, de presidir àquela "Congregação de Advogados".

As suas forças, nos últimos tempos, já iam fraquejando. Aquele cérebro portentoso, que concebera tantas obras primas - "Ações de despejo e alugueres", "A ação possessoria", "Cinco estudos", "Na vida jurídica", "Discursos e conferencias", "A Hipotéca", - cansára-se de trabalhar. Ainda assim, de quando em quando, aclarava a discussão de causas em debate, com os seus famosos pareceres. Foi obrigado a deixar a presidencia da Ordem. E quando esta inaugurou o seu retrato, na sala de sessões do Conselho, foi temerosos que nós, os seus amigos, vimo-lo chegar, emocionado, para que ante êle a palavra mágica de Plinio Barreto jorrasse, numa cascata de maravilhas. .

Pelos amplos salóes de sua casa, à Avenida Paulista, 392, vagava êle como uma sombra, nos seus derradeiros dias. Olhava fixamente para tudo, como a se despedir de cada movel, de cada livro, de cada quadro.

A sua coleção artistica era um tesouro. Télas dos mais variados autores e dos mais reputados. Assinalavam, muitas vezes, a impressão duradoura de uma viagem, ou um aspeto de paisagem, de que jamais se olvidára.

A outro apreciador da pintura, Waldemar TeIxeIra DE Carvalho, a quem estimava como a um filho, confidenciava sentir que o seu fim estava próximo. Custava-lhe apartar-se de sua casa, de seus quadros, de sua bibliotéca, de sua querida d. Ana, a quem se entristecia deixar sózinha neste mundo. "Não tivemos filhos", acrescentava; "eu tenho de ser para ela o marido e o filho ao mesmo tempo"...

$O$ seu grande consolo era a música e a companhia da esposa dileta, a quem tomára pelas mãos ainda obscuro magistrado no interior de São Paulo, para a gloriosa ascenção que juntos realizaram. 
Ninguem lhe falava à alma como Chopin, cujas berceuses e preludios, valsas e polonaisếs, executava ao piano com grande sentimento. Nada prezava mais do que a sua arte. Ministro das Relações Exteriores, surpreendeu uma noite os convidados, em sua residencia, após o jantar, dedilhando no teclado o minueto de Paderewsky.

Epitacio Pessoa, tambem amante da bôa música, era, êle proprio, frautista eximio. Por isso, logo após a posse de Arthur Bernardes, uma revista do Rio, numa charge espirituosissima, com a qual Azevedo Marques se deleitou, pôs, sobre a mesa de trabalho do antigo ministro, no Itamaratí, umas partituras de piano e frauta...

A sua última alegria foi quando recebeu em casa, levado pela Congregação inteira, o título de profęssor emérito. Em verdade, tardámos demasiadamente; mas, a nossa demóra fôra traçada pelo destino, para que essa láurea fosse o premio derradeiro desse trabalhador infatigavel.

Trabalhára tanto! Mas, valeria a pena tê-lo feito? A Miguel Reale, que um dia o visitava, teve esta frase, de uma doce filosofia: "Consumimos cincoenta anos preparando a nossa vida; depois, velhos e cansados, passamos o resto da existencia recordando a mesma vida"...

Cerca de um mềs antes de sua morte, passando de bonde pela Avenida Paulista, vi o mestre quando descia a escada de sua residencia, para o jardim. Parecia satisfeito. Era uma manhã esplendida de sol e buscava o carinho das flores...

A 24 de maio de 1943, pouco depois das oito horas, chegava eu à Faculdade, para a aula costumeira. Ao entrar no Largo de São Francisco, senti o coração opresso, enxergando, à frente desta Casa, a bandeira em funeral. À porta da Academia, encontrei Benedicto Galvão, espírito adamantino e coração de santo, a quem tambem levariamos, vinte dias mais tarde, ao cemiterio de São Paulo. Estendeu-me as mãos, emocionado, e indagou: - Será o Azevedo Marques? Desgraçadamente, eu tinha esse pressentimento... 
Subimos juntos até a sala da diretoria, onde se confirmou o nosso vaticinio. Minutos após, chegava Nó́ AzEvedo e nós tres, em nome da Ordem dos Advogados, fomos visitar o amigo queridissimo.

No hall, o mesmo painel, com os amplos portais marroquinos, destacando-se ao fundo as luzes da praia de Biarritz, no soberbo flagrante de Dupuy. E naquela sala, tão minha conhecida, onde ainda escutava o sussurro de sua voz aveludada, repousava, revestido de sua béca de professor, o rosto macerado e triste, o grande mestre, cuja obra hoje iexaltamos.

"Etait-ce de la mort, la pâle majesté, “Ou le premier rayon de l'immortalité?"

Não sei a razão pela qual, contemplando o esquife sagrado, acudiram-me à mente os versos de LAMARTINE, sobre "A Morte de Sócrates". Azevedo Marques não morrera e eu ali me encontrava para recolher de seus labios a derradeira lição de filosofia...

"Vous qui près du tombeau, venez pour m'écouter,

"Je suis un cygne aussi, je meurs, je puis chanter!"

A Faculdade de Direito, no primeiro aniversario do desaparecimento desse ilustre filho, traz-lhe a homenagem de sua saudade, pela palavra inspirada de Vicente Ráo. O Conselho da Ordem dos Advogados, em São Paulo, no altar em que se consagra essa vida magnifica, vem depor a sua oblata, pela voz rouquenha de um estudante, que com êle aprendeu. E, como Platão, em referencia a Sócrates, rendo graças aos céus, por haver sido discípulo de José Manuel. de Azevedo Marques. 